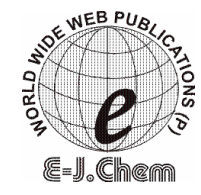

http://www.e-journals.net
ISSN: 0973-4945; CODEN ECJHAO

E-Journal of Chemistry

Vol. 5, No.1, pp. 155-162, January 2008

\title{
Synthesis, Characterization and Antimicrobial Studies of 3-[(2-Hydroxy-quinolin-3-ylmethylene)-amino]-2-phenyl- 3H-quinazolin-4-one and its Metal(II) Complexes
}

\author{
K. SIDDAPPA*, TUKARAM REDDY, M .MALLIKARJUN and C V.REDDY\# \\ "Department of Studies and Research in Chemistry, \\ Gulbarga University, Gulbarga-585 106,Karnataka - India \\ ${ }^{\#}$ C.B. Arts and Science Degree College, Bhalki, Dist. Bidar. Karnataka-India \\ siddappa_65@rediffmail.com
}

Received 20 July 2007; Accepted 22 September 2007

\begin{abstract}
A new complexes of the type $\mathrm{ML}_{2}$ and $\mathrm{M}^{\prime} \mathrm{L}$ [where $\mathrm{M}=\mathrm{Cu}(\mathrm{II})$, $\mathrm{Co}(\mathrm{II})$, and $\mathrm{Ni}(\mathrm{II})$ and $\mathrm{M}^{\prime}=\mathrm{Zn}(\mathrm{II}), \mathrm{Cd}(\mathrm{II})$ and $\left.\mathrm{Hg}(\mathrm{II})\right] . \mathrm{L}=3$-[(2-hydroxyquinolin-3-ylmethylene)-amino]-2-phenyl-3H-quinazolin-4-one, (HQMAPQ) Schiff base have been synthesized and characterized by elemental analysis, magnetic susceptibility, molar conductance, IR, ${ }^{1} \mathrm{H}$ NMR, UV-Visible and ESR data. The studies indicate the HQMAPQ acts as doubly monodentate bridge for metal(II) ions and form mononuclear complexes. The complexes $\mathrm{Ni}(\mathrm{II}), \mathrm{Co}(\mathrm{II})$ and $\mathrm{Cu}$ (II) complexes are found to be octahedral, where as $\mathrm{Zn}(\mathrm{II}), \mathrm{Cd}(\mathrm{II})$ and $\mathrm{Hg}$ (II) complexes are four coordinated with tetrahedral geometry. The synthesized ligand and its metal(II) complexes were screened for their antimicrobial activity.
\end{abstract}

Keywords: Quinazoline, Metal(II) complexes, Antimicrobial activity, Spectral data.

\section{Introduction}

Among a wide variety of nitrogen heterocyles that have been explored for developing pharmaceutically important molecules, the quinazoline have played an important role in medicinal chemistry and subsequently have emerged as a pharmacophore ${ }^{1}$. Recently, nitraquazone, a quinazoline derivative has been found to possess potent phosphodiesterase inhibitory activity ${ }^{2}$ which is potentially useful in the treatment of asthma ${ }^{3}$. A few of the activities associated with quinazoline nucleus are hypotensive activity ${ }^{4}$, anticonvulsant ${ }^{5}$, anticoagulant $^{6}$, anti-fibrillatory ${ }^{7}$, cardiac stimulant ${ }^{8}$, diuretic $^{9}$, antibacterial ${ }^{10}$ and antiviral ${ }^{11-13}$. Because of their biological relevance interesting to spectral and magnetic properties of ligand and its metal complexes are being used generally synthetic building blocks due to their chemical and biological relevance. The literature survey reveals that the reaction of 
quinazoline hydrazide(PQH) and quinolinaldehyde(HQA) schiff base have not been reported so far. Hence it was thought to undertake such study. Therefore, it was thought worthwhile to synthesize novel quinazoline ligand (HQMAPQ) and its metal(II) complexes are characterized.

The present paper deals with the synthesis, spectral and magnatochemical studies of metal(II) complexes with the following ligand (HQMAPQ) (Fig. 1).

\section{Experimental}

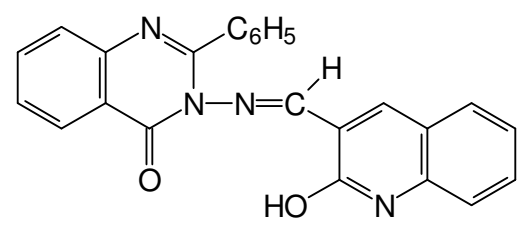

Figure 1. Structure of HQMAPQ ligand

All the reagents used were of analytical grade and were used without further purification.

\section{Preparation of 3-amino-2-phenylquinazoline-4-one $(P Q H)$}

A mixture of 2-phenyl-3,1-benzoxazine-4-one ${ }^{14}(0.1$ mole $)$ and hydrazine hydrate $(0.1$ mole) in ethanolic solution was refluxed for 8 hours. The excess of solvent was then distilled off, and the resulting solid was dried and recrystallised from ethanol, M.P.: $142{ }^{\circ} \mathrm{C}$ yield $72 \%$.

Preparation of 3-[(2-Hydroxyquinoline-3-ylmethylene)-amino]-2-phenyl-3H-quina zoline-4-one (HQMAPQ)

The ligand [HQMAPA] were prepared by condensation of 3-amino-2-phenylquinazoline-4one (PQH) (0.01 mole) and 3-formyl-2-hydroxyquinoline (HQA) (0.01 mole) in ethanol was refluxed on water bath for 6-7 $\mathrm{h}$ in presence of few drops of acetic acid. The reaction mixture was cooled to room temperature the separated ligand was filtered, washed and recrystallized from alcohol. The purity of the ligand (HQMAPQ) (Fig. 2) was checked by TLC.

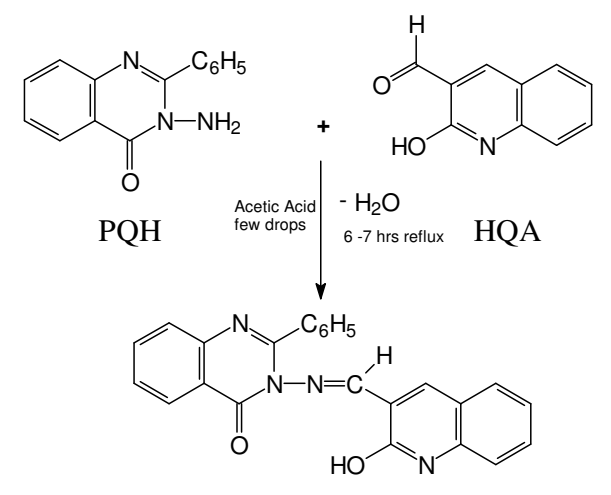

Figure 2. Synthesis of HQMAPQ

Preparation of metal(II) complexes

An ethanolic solution of ligand (HQMAPQ) (0.01 mole) was added a hot ethanolic solution of metal(II) chloride ( 0.01 mole) the reaction mixture was refluxed on water bath for $4 \mathrm{~h}$ to 
get a clear solution. $0.5 \mathrm{~g}$ of sodium acetate was added to the reaction mixture to adjust the $\mathrm{pH} 7-8$ of the solution. The reaction mixture was further refluxed for $2 \mathrm{~h}$ until a precipitate appeared after cooling, the solid was filtered off, washed with water and then little hot ethanol apparent dryness and dried in vacuum over anhydrous calcium chloride in a desiccator (yield 60-75\%).

\section{Analysis}

The complexes were analyzed for their metal and chloride contents were determined by standard methods ${ }^{15}$.

\section{Physical Measurements}

Infrared spectra of the ligand and its metal(II) complexes in $\mathrm{KBr}$ pellets were recorded in the spectral range 4000-350 $\mathrm{cm}^{-1}$ range with Perkin Elmer Spectrum one FT-IR spectrometer. UV-Visible spectra were recorded on an Elico SL-164 DOUBLE BEAM UV-Vis Spectrophotometer in the range of 200-1200 nm. Magnetic susceptibilities were measured on a Guoy Balance at a room temperature using $\mathrm{HgCo}(\mathrm{NCS})_{4}$ as calibrant. The molar conductance of the complexes were measured on ELICO CM-82 conductivity bridge in DMF solution at conc. $\sim 10^{-3}$ M. ${ }^{1} \mathrm{H}$ NMR spectra were recorded on AMX-400 NMR spectrometer, using TMS as internal standard and DMSO as a solvent. The elemental analysis (CHN) and ESR spectra recorded on STIC Cochin.

\section{Results and Discussion}

All the complexes were sparingly soluble in common organic solvents but soluble in DMF, DMSO and acetonitrile. The analytical data indicates that the complexes are agree well with 1:1 metal to ligand stoichiometry for $\mathrm{Zn}(\mathrm{II}), \mathrm{Cd}(\mathrm{II})$ and $\mathrm{Hg}(\mathrm{II})$ and $1: 2$ for $\mathrm{Cu}(\mathrm{II}), \mathrm{Co}(\mathrm{II})$ and $\mathrm{Ni}(\mathrm{II})$ complexes shown in (Table 1). The observed molar conductance (Table 1) values measured in DMF solution fall in the range $\left(13-20 \mathrm{ohm}^{-1} \mathrm{~cm}^{2} \mathrm{~mol}^{-1}\right)$. These observed values of the molar conductance are well within the expected range for non-electrolyes ${ }^{16}$.

\section{Magnetic Susceptibility}

The magnetic moments obtained at room temperature for the complexes of $\mathrm{Cu}(\mathrm{II}), \mathrm{Ni}(\mathrm{II})$ and $\mathrm{Co}$ (II) are listed (Table 1). $\mathrm{Cu}$ (II) complex exhibits magnetic moment 1.95 B.M. which is less than the normal value ${ }^{17}(1.84-2.20$ B.M.). The lowered magnetic moment value observed for $\mathrm{Cu}(\mathrm{II})$ complex under present study is due to distorted octahedral geometry ${ }^{18}$. The Co(II) complex shows magnetic moment of 4.86 B.M. the spin free octahedral complex of $\mathrm{Co}(\mathrm{II})$ are reported to exhibit magnetic moment in the range of 4.46- 5.53 B.M. ${ }^{19}$. Hence observed magnetic moment for the Co(II) complex under study indicates it has an octahedral configuration. The $\mathrm{Ni}(\mathrm{II})$ complex shows magnetic moment of 2.95 B.M. The magnetic moment of octahedral $\mathrm{Ni}(\mathrm{II})$ complex are reported to exhibit magnetic moment in the range of $2.80-3.40$ B.M. ${ }^{20}$ including spin orbital coupling contribution from ${ }^{3} \mathrm{~A}_{2 \mathrm{~g}}$ and higher ${ }^{3} \mathrm{~T}_{2 \mathrm{~g}}$ states. Hence the observed magnetic moment for the $\mathrm{Ni}$ (II) complex suggest that it may have octahedral geometry.

\section{Electronic spectra}

The electronic spectral data of $\mathrm{Cu}(\mathrm{II}), \mathrm{Co}(\mathrm{II})$ and $\mathrm{Ni}(\mathrm{II})$ complexes were recorded in $\mathrm{DMF}$ as shown in Table 3.They have been studied with the view to obtain more information on stereochemistry of the complexes and to procure more support for the conclusion, deduced with the help of magnetic data. The light green colored $\mathrm{Cu}(\mathrm{II})$ complex exhibits a broad 
asymmetric band in the region $16395-12195 \mathrm{~cm}^{-1}$ with maxima at $12210 \mathrm{~cm}^{-1}$ in an distorted octahedral geometry ${ }^{21}$. The broadness of the band may be due to dynamic Jahn-Teller distortion and is assigned to ${ }^{2} \mathrm{~T}_{2 \mathrm{~g}} \rightarrow{ }^{2} \mathrm{E}_{\mathrm{g}}$ transitions.

The Co(II) complex (light purple) of the electronic absorption bands appears at 9992 and $20085 \mathrm{~cm}^{-1}$, due to ${ }^{4} \mathrm{~T}_{1 \mathrm{~g}}(\mathrm{~F}) \rightarrow{ }^{4} \mathrm{~A}_{2 \mathrm{~g}}\left(\mathrm{v}_{1}\right)$ and ${ }^{4} \mathrm{~T}_{1 \mathrm{~g}}(\mathrm{~F}) \rightarrow{ }^{4} \mathrm{~T}_{1 \mathrm{~g}}(\mathrm{P})\left(\mathrm{V}_{3}\right)$ transition, respectively, in an octahedral environment ${ }^{22,23}$. The bands due to the ${ }^{4} \mathrm{~T}_{1 \mathrm{~g}}(\mathrm{~F}) \rightarrow{ }^{4} \mathrm{~A}_{2 \mathrm{~g}}(\mathrm{~F})\left(\mathrm{V}_{2}\right)$ transition could not observed because of its very low intensity. However the position of the $v_{2}$ band has been computed $\left(15439 \mathrm{~cm}^{-1}\right)$ by the equation. $v_{2}=v_{1+}$ 10Dq. The intense band around $30000 \mathrm{~cm}^{-1}$ may be a charge transfer band. The ligand field parameter such as Dq, B', $\beta$ and $\beta \%$ have been calculated by using band-fitting equation given by Underhill and Billing ${ }^{24}$. The crystal field splitting energy (Dq) value at $825 \mathrm{~cm}^{-1}$. These values are well within the range reported are most of the octahedral $\mathrm{Co}(\mathrm{II})$ complexes. The $\mathrm{Co}(\mathrm{II})$ complex under present investigation process interelectronic repulsion parameter (B') $930 \mathrm{~cm}^{-1}$. The Racha parameter (B) is less than free ion value (971) suggesting a considerable orbital overlap and delocalization of electrons on the metal ion. The nephelauxetic ratio $(\beta)$ for the present $\mathrm{Co}(\mathrm{II})$ complex (0.95). This is less than one, suggesting partial covalency in the metal ligand bond. The values Dq, $\beta \%$ LFSE and $v_{2} / v_{1}$ (Table 2) suggest the octahedral geometry for $\mathrm{Co}(\mathrm{II})$ complex $^{25}$. The electronic spectrum of $\mathrm{Ni}(\mathrm{II})$ complex shows two bands at 15151 and $25316 \mathrm{~cm}^{-1}$ assignable to ${ }^{3} \mathrm{~A}_{2 \mathrm{~g}} \rightarrow{ }^{3} \mathrm{~A}_{1 \mathrm{~g}}(\mathrm{~F})\left(\mathrm{v}_{2}\right)$ and ${ }^{3} \mathrm{~A}_{2 \mathrm{~g}} \rightarrow{ }^{3} \mathrm{~T}_{1 \mathrm{~g}}(\mathrm{P})\left(\mathrm{v}_{3}\right)$ transitions respectively, in an octahedral environment $t^{26}$. The lowest band $\mathrm{v}_{2}(10 \mathrm{Dq})$ was not observed due to limited range of the instrument used. However, it is calculated by using equation suggested by Billing and Underhill. Racha parameter $\mathrm{B}^{1}$ is less than the free ion value of $1040 \mathrm{~cm}^{-1}$ indicating the covalent character of the complex. The ratio $v_{2} / v_{1}$ and $\beta \%$ are further support the octahedral geometry around the $\mathrm{Ni}(\mathrm{II})$ ion $^{27}$.

\section{Infrared Spectra}

The significant IR bands for the ligand (HQMAPQ) as well as for its metal (II) complexes and their tentative assignments are compiled and represented in Table 2. The broad band observed at $3435 \mathrm{~cm}^{-1}$ in the IR spectra of the ligand (HQMAPQ) assigned to $\mathrm{v}(\mathrm{OH})$, which were found to have disappeared in all their respective complexes, thereby indicating the involvement of phenolic oxygen is bonding with metal ions through deprotonation $^{28}$. A strong sharp band observed at $1659 \mathrm{~cm}^{-1}$ is assigned to quinazoline ring $v(\mathrm{C}=\mathrm{O})$, which was shifted to $33-57 \mathrm{~cm}^{-1}$ in all complexes ${ }^{29}$, indicates the involvement of quinazoline ring carboxyl in complexation with metal $\operatorname{ion}^{30}$, the band at $1600 \mathrm{~cm}^{-1}$ is assigned to the azomethine $v_{(\mathrm{C}=\mathrm{N})}$ group ${ }^{31}$, lowering of $v_{(\mathrm{C}=\mathrm{N})} 24-43 \mathrm{~cm}^{-1}$ in the complexes as compared to its ligand is due to reduction of double bond character carbon-nitrogen bond of the azomethine group ${ }^{32}$.

The band observed at $1273 \mathrm{~cm}^{-1}$, of the ligand is attributed to phenolic $v_{(\mathrm{C}-\mathrm{O})}$ in view of previous observations ${ }^{21}$. This band is shifted to higher frequency and is found in the region $1301-1316 \mathrm{~cm}^{-1}$ for the complexes. Thus, this further confirms the involvement of phenolic $\mathrm{OH}$ in the complex formation. The low frequency skeletal vibrations due to $\mathrm{M}-\mathrm{O}$ and $\mathrm{M}-\mathrm{N}$ stretching provide direct evidence for complexation. In the present investigation, the bands in the 534-525 $\mathrm{cm}^{-1}$ and $445-425 \mathrm{~cm}^{-1}$ region for $v_{\mathrm{M}-\mathrm{O}}$ and $v_{\mathrm{M}-\mathrm{N}}$ vibration respectively ${ }^{33}$. The bands due to $\mathrm{v}_{(\mathrm{M}-\mathrm{Cl})}$ were observed in the $364-352 \mathrm{~cm}^{-1}$ region and are characteristic of chlorine atom in $\mathrm{Zn}(\mathrm{II}), \mathrm{Cd}(\mathrm{II})$ and $\mathrm{Hg}(\mathrm{II})$ complexes is further confirmed by quantitative chloride estimation. 


\section{${ }^{1}$ H NMR spectra}

Spectrum of ${ }^{1} \mathrm{H}$ NMR in DMSO- $\mathrm{d}_{6}$ solvent used. In ligand (HQMAPQ) showed sharp peak at $\delta 12.2(\mathrm{~S}, 1 \mathrm{H})$ due to $\mathrm{OH}$ at 2-position of phenyl ring of quinoline moiety has resonated, but in the case of $\mathrm{Cd}(\mathrm{II})$ complex which has been disappeared indicating the involvement of phenolic oxygen in the coordination via deprotonation ${ }^{34}$. The peak appears at $\delta 8.8(\mathrm{~S}, 1 \mathrm{H},-\mathrm{CH}=\mathrm{N})$ due to the azomethine group in ligand but in case of $\mathrm{Cd}(\mathrm{II})$ complex the peak observed at $8.6(\mathrm{~S}, 1 \mathrm{H},-\mathrm{CH}=\mathrm{N})$. The fourteen aromatic protons due to quinazoline and phenyl rings have resonated in region $\delta 7.0-8.6(\mathrm{~m}, 14 \mathrm{H}, \mathrm{Ar}-\mathrm{H})$ as a multiplet in $\mathrm{Cd}(\mathrm{II})$ complex the fourteen aromatic protons have been observed in the region $\delta$ 6.92-8.42 (m, 14H, Ar-H) as multiplet. The $\mathrm{Cd}(\mathrm{II})$ complex suggest coordination of the phenolic $\mathrm{OH}$ with metal ion ${ }^{35}$.

\section{ESR Spectrum}

ESR spectrum of $\mathrm{Cu}(\mathrm{II})$ complexes of ligand (HQMAPQ) scanned at room temperature (Table 4) using DPPH as a standard showed a broadened feature without hyperfine splitting due to the dipolar interaction from the ESR spectrum of a set of magnetic parameter $\mathrm{g}_{\|} 2.053$ and $\mathrm{g}_{\perp}$ 2.0276. The observed ESR spectrum is characteristic of distorted octahedral geometry $g$ value averaged to overall directions and $G$ which is measure of extent of exchange interaction between metal ion have been calculated. In present case the value of $\mathrm{G}$ was found to be 4.028 according to Hathway ${ }^{36}$. If $G$ value is greater than 4 , the spin exchange interaction is negligible where as $G$ value less than 4 indicate considerable interaction between metal ions in solid complex clearly indicate that $\mathrm{Cu}(\mathrm{II})$ ion in the complex is mono-nuclear nature of the complex.

\section{Antimicrobial Activity}

Antimicrobial activity was carried out using the cup-plate method ${ }^{37}$. The antimicrobial activity results of the screened compounds are given in the Table 5. The ligand (HQMAPQ) and its $\mathrm{Cu}(\mathrm{II}), \mathrm{Co}(\mathrm{II}), \mathrm{Ni}(\mathrm{II}), \mathrm{Zn}(\mathrm{II}), \mathrm{Cd}(\mathrm{II})$ and $\mathrm{Hg}(\mathrm{II})$ complexes have been tested for their antibacterial activity ${ }^{38}$, against $E$. coli and $S$. aureus and antifungal activity ${ }^{39}$ against $A$. niger and $A$. flavous at $100 \mu \mathrm{g} / 0.1 \mathrm{~cm}^{3}$ concentration. The standard drugs streptomycin and chlotrimazole were also tested for their antibacterial and antifungal activity at the same concentration under the conditions similar to that of the test compounds. The antibacterial activity results revealed that the ligand and its complexes shown weak to good activity. The ligand and its $\mathrm{Cu}$ (II) and $\mathrm{Ni}$ (II) complexes shows weakly active with the zone of inhibition 11-13 $\mathrm{mm}$ against the both organisms when compared to the standard drug streptomycin. The Co(II) and Cd(II) complexes shows active and moderate activity as compared to its ligand with zone of inhibition 14-16 and 17-18 mm respectively. The $\mathrm{Zn}$ (II) and $\mathrm{Hg}$ (II) complexes have exhibited good activity with the zone of inhibition 19 to $20 \mathrm{~mm}$ when compared to the standard drug streptomycin.

The antifungal activity results revealed that the ligand and its $\mathrm{Cu}(\mathrm{II}), \mathrm{Co}(\mathrm{II}), \mathrm{Ni}(\mathrm{II})$, $\mathrm{Zn}(\mathrm{II}), \mathrm{Cd}(\mathrm{II})$ and $\mathrm{Hg}(\mathrm{II})$ complexes have exhibited weak to good activity. The ligand and its $\mathrm{Cu}$ (II) and $\mathrm{Co}$ (II) complexes shows weak activity when compared to the standard drug chlotrimazole. The $\mathrm{Ni}(\mathrm{II})$ and $\mathrm{Cd}(\mathrm{II})$ complexes shows active and moderate activity as compared to its ligand with the zone of inhibition 15-16 and 17-18 mm respectively.

The $\mathrm{Zn}$ (II) and $\mathrm{Hg}(\mathrm{II})$ complexes have exhibited good activity with the zone of inhibition 19-21 mm when compared to the standard drug chlotrimazole. 
Table 1 Analytical, magnetic susceptibility and molar conductance data of the ligand [HQMAPQ] and its metal (II) complexes

\begin{tabular}{|c|c|c|c|c|c|c|c|c|c|c|}
\hline \multirow{2}{*}{ Ligand / Complex } & \multirow{2}{*}{$\begin{array}{l}\text { Mol. } \\
\text { Wt. }\end{array}$} & \multirow{2}{*}{$\begin{array}{l}\text { M.P. } \\
\left({ }^{0} \mathrm{C}\right)\end{array}$} & \multirow{2}{*}{$\begin{array}{l}\text { Yield } \\
(\%)\end{array}$} & \multicolumn{5}{|c|}{ Found / (Calculated) $\%$} & \multirow{2}{*}{$\begin{array}{r}\mu_{\text {eff }} \\
\text { B.M. }\end{array}$} & \multirow{2}{*}{$\begin{array}{c}\text { Molar } \\
\text { Conductance } \\
{ }^{\wedge} \mathrm{m} \mathrm{Ohm}^{-1} \\
\mathrm{~cm}^{2} \mathrm{~mol}^{-1}\end{array}$} \\
\hline & & & & $\mathrm{C}$ & $\mathrm{H}$ & $\mathrm{N}$ & M & $\mathrm{Cl}$ & & \\
\hline $\mathrm{C}_{24} \mathrm{H}_{16} \mathrm{~N}_{4} \mathrm{O}_{2}$ & 392.41 & 245 & 80 & $73.21(73.46)$ & $4.15(4.11)$ & $14.12(14.28)$ & - & - & - & - \\
\hline$\left[\mathrm{Cu}\left(\mathrm{C}_{24} \mathrm{H}_{15} \mathrm{~N}_{4} \mathrm{O}_{2}\right)_{2}\right]$ & 846.35 & 282 & 70 & $68.02(68.12)$ & $3.41(3.57)$ & $13.42(13.27)$ & $7.41(7.51)$ & - & 1.95 & 15.15 \\
\hline$\left[\mathrm{Co}\left(\mathrm{C}_{24} \mathrm{H}_{15} \mathrm{~N}_{4} \mathrm{O}_{2}\right)_{2}\right]$ & 841.74 & 286 & 65 & $68.26(68.49)$ & $3.42(3.59)$ & $13.15(13.31)$ & $7.21(7.00)$ & - & 4.86 & 18.38 \\
\hline$\left[\mathrm{Ni}\left(\mathrm{C}_{24} \mathrm{H}_{15} \mathrm{~N}_{4} \mathrm{O}_{2}\right)_{2}\right]$ & 841.50 & 291 & 68 & $68.34(68.51)$ & $3.72(3.59)$ & $13.65(13.32)$ & $6.69(6.97)$ & - & 2.95 & 19.49 \\
\hline $\left.\mathrm{Zn}\left(\mathrm{C}_{24} \mathrm{H}_{15} \mathrm{~N}_{4} \mathrm{O}_{2}\right) \mathrm{Cl}\right]$ & 492.24 & 284 & 60 & $58.52(58.56)$ & $3.02(3.07)$ & $11.25(11.38)$ & $13.25(13.28)$ & $7.15(7.20)$ & Diamag & 13.13 \\
\hline $\left.\mathrm{Cd}\left(\mathrm{C}_{24} \mathrm{H}_{15} \mathrm{~N}_{4} \mathrm{O}_{2}\right) \mathrm{Cl}\right]$ & 539.27 & 292 & 65 & $53.41(53.45)$ & $2.78(2.80)$ & 10.35 (10.39) & $20.80(20.85)$ & $6.52(6.57)$ & Diamag & 16.26 \\
\hline $\left.\mathrm{Hg}\left(\mathrm{C}_{24} \mathrm{H}_{15} \mathrm{~N}_{4} \mathrm{O}_{2}\right) \mathrm{Cl}\right]$ & 627.44 & 299 & 75 & $45.90(45.94)$ & $2.38(2.41)$ & $8.91(8.93)$ & $31.93(31.97)$ & $5.62(5.65)$ & Diamag & - \\
\hline
\end{tabular}

Table 2. Electronic spectral data and ligand field parameters of $\mathrm{Cu}(\mathrm{II}), \mathrm{Co}(\mathrm{II})$ and $\mathrm{Ni}(\mathrm{II})$ quinazoline complexes

\begin{tabular}{|c|c|c|c|c|c|c|c|c|c|c|}
\hline Complexes & $v_{1}$ & $v_{2}$ & $v_{3}$ & $\mathrm{Dq}_{1}$ & $\mathrm{~B}^{1}$ & $\beta$ & $\beta \%$ & $v_{2} / v_{1}$ & $v_{3} / v_{2}$ & LFSE \\
\hline$\left[\mathrm{Cu}\left(\mathrm{C}_{24} \mathrm{H}_{15} \mathrm{~N}_{4} \mathrm{O}_{2}\right)_{2}\right]$ & - & 12195 & 16395 & 1429 & - & - & - & - & - & 24.50 \\
\hline$\left[\mathrm{Co}\left(\mathrm{C}_{24} \mathrm{H}_{15} \mathrm{~N}_{4} \mathrm{O}_{2}\right)_{2}\right]$ & 9992 & 15439 & 20085 & 825 & 930 & 0.958 & 15.03 & 1.54 & 1.30 & 14.17 \\
\hline$\left[\mathrm{Ni}\left(\mathrm{C}_{24} \mathrm{H}_{15} \mathrm{~N}_{4} \mathrm{O}_{2}\right)_{2}\right]$ & 10810 & 15151 & 25316 & 932 & 834 & 0.802 & 19.80 & 1.4015 & 1.6709 & 31.954 \\
\hline
\end{tabular}

Table 3. Important spectral IR bands of the ligand [HQMAPQ] and its metal (II) complexes

\begin{tabular}{lccccccc}
\hline \multicolumn{1}{c}{ Ligand/ complexes } & $v_{\mathrm{OH}}$ & $v_{\mathrm{C}=\mathrm{O}}$ & $v_{\mathrm{C}=\mathrm{N}}$ & $v_{\mathrm{C}-\mathrm{O}}$ & $v_{\mathrm{M}-\mathrm{O}}$ & $v_{\mathrm{M}-\mathrm{N}}$ & $v_{\mathrm{M}-\mathrm{Cl}}$ \\
\hline $\mathrm{C}_{24} \mathrm{H}_{16} \mathrm{~N}_{4} \mathrm{O}_{2}$ & 3435 & 1659 & 1600 & 1273 & - & - & - \\
{$\left[\mathrm{Cu}\left(\mathrm{C}_{24} \mathrm{H}_{15} \mathrm{~N}_{4} \mathrm{O}_{2}\right)_{2}\right]$} & - & 1608 & 1569 & 1302 & 530 & 427 & - \\
{$\left[\mathrm{Co}\left(\mathrm{C}_{24} \mathrm{H}_{15} \mathrm{~N}_{4} \mathrm{O}_{2}\right)\right.$} & - & 1614 & 1568 & 1301 & 534 & 428 & - \\
{$\left[\mathrm{Ni}\left(\mathrm{C}_{24} \mathrm{H}_{15} \mathrm{~N}_{4} \mathrm{O}_{2}\right)_{2}\right]$} & - & 1613 & 1576 & 1316 & 530 & 425 & - \\
{$\left[\mathrm{Zn}\left(\mathrm{C}_{24} \mathrm{H}_{15} \mathrm{~N}_{4} \mathrm{O}_{2}\right) \mathrm{Cl}\right]$} & - & 1626 & 1567 & 1315 & 530 & 425 & 358 \\
{$\left[\mathrm{Cd}\left(\mathrm{C}_{24} \mathrm{H}_{15} \mathrm{~N}_{4} \mathrm{O}_{2}\right) \mathrm{Cl}\right]$} & - & 1621 & 1557 & 1312 & 531 & 445 & 364 \\
{$\left[\mathrm{Hg}\left(\mathrm{C}_{24} \mathrm{H}_{15} \mathrm{~N}_{4} \mathrm{O}_{2}\right) \mathrm{Cl}\right]$} & - & 1602 & 1567 & 1301 & 525 & 435 & 352 \\
\hline
\end{tabular}

Table 4. ESR data of the $\mathrm{Cu}(\mathrm{II})$ complex of the ligand [HQMAPQ]

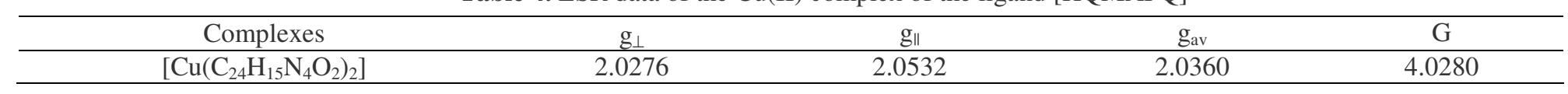


Table 5. Antimicrobial activity of the ligand [HQMAPQ] and its metal(II) complexes

\begin{tabular}{lcccc}
\hline \multirow{2}{*}{ Compound } & \multicolumn{2}{c}{$\begin{array}{c}\text { Antibacterial Activity of zone } \\
\text { of inhibition, mm }\end{array}$} & $\begin{array}{c}\text { Antifungal Activity of zone of } \\
\text { inhibition, mm }\end{array}$ \\
\cline { 2 - 5 } & E. coli & S. aureus & A. niger & A. falvous \\
\hline $\mathrm{C}_{24} \mathrm{H}_{16} \mathrm{~N}_{4} \mathrm{O}_{2}$ & 11 & 12 & 12 & 11 \\
{$\left[\mathrm{Cu}\left(\mathrm{C}_{24} \mathrm{H}_{15} \mathrm{~N}_{4} \mathrm{O}_{2}\right)_{2}\right]$} & 11 & 13 & 13 & 12 \\
{$\left[\mathrm{Co}\left(\mathrm{C}_{24} \mathrm{H}_{15} \mathrm{~N}_{4} \mathrm{O}_{2}\right)_{2}\right]$} & 14 & 16 & 12 & 14 \\
{$\left[\mathrm{Ni}\left(\mathrm{C}_{24} \mathrm{H}_{15} \mathrm{~N}_{4} \mathrm{O}_{2}\right)_{2}\right]$} & 13 & 12 & 15 & 16 \\
{$\left[\mathrm{Zn}\left(\mathrm{C}_{24} \mathrm{H}_{15} \mathrm{~N}_{4} \mathrm{O}_{2}\right) \mathrm{Cl}\right]$} & 19 & 20 & 20 & 19 \\
{$\left[\mathrm{Cd}\left(\mathrm{C}_{24} \mathrm{H}_{15} \mathrm{~N}_{4} \mathrm{O}_{2}\right) \mathrm{Cl}\right]$} & 18 & 17 & 18 & 17 \\
{$\left[\mathrm{Hg}\left(\mathrm{C}_{24} \mathrm{H}_{15} \mathrm{~N}_{4} \mathrm{O}_{2}\right) \mathrm{Cl}\right]$} & 20 & 19 & 21 & 20 \\
Streptomycin & 24 & 21 & - & - \\
Chlorotrimazole & - & - & 24 & 23 \\
DMF (Control) & 0 & 0 & 0 & 0 \\
Bore size & 08 & 08 & 08 & 08 \\
\hline
\end{tabular}

\section{Conclusion}

The elemental analysis, magnetic susceptibility, electronic, IR, ${ }^{1} \mathrm{H}$ NMR and ESR spectral observations projects the following structures (Fig 3 and Fig 4) for these complexes where in $\mathrm{Cu}(\mathrm{II}), \mathrm{Co}(\mathrm{II})$ and $\mathrm{Ni}(\mathrm{II})$ exhibit coordination number of six, $\mathrm{Zn}(\mathrm{II}), \mathrm{Cd}(\mathrm{II})$ and $\mathrm{Hg}(\mathrm{II})$ are four coordinated tetrahedral geometry.

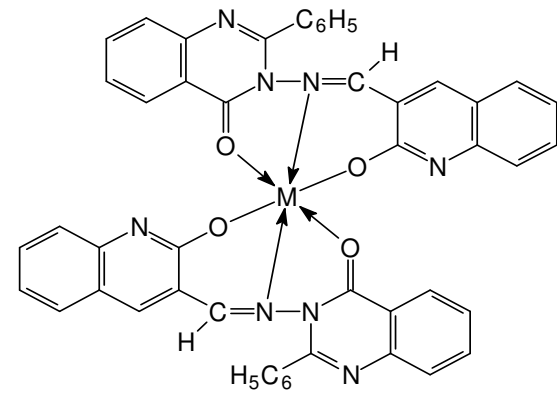

Figure 3. Structure of complex. $\mathrm{M}=\mathrm{Cu}(\mathrm{II}), \mathrm{Co}(\mathrm{II})$ and $\mathrm{Ni}(\mathrm{II})$

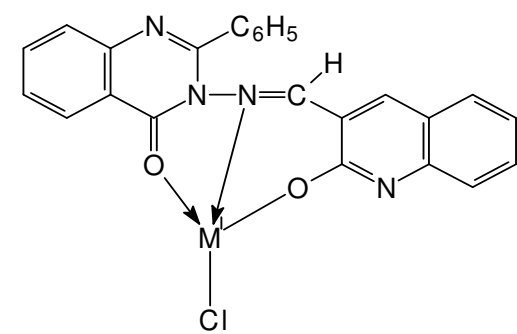

Figure 4. Structure of complex. $\mathrm{M}^{\prime}=\mathrm{Zn}(\mathrm{II}), \mathrm{Cd}(\mathrm{II})$ and $\mathrm{Hg}(\mathrm{II})$

\section{Acknowledgement}

The authors are thankful to the Chairman, Department of Chemistry, Gulbarga University, Gulbarga for providing the facilities. They also thank Chairman of to Department of Microbiology and Botany Gulbarga University, Gulbarga for carrying microbial activities. They also thank IISc Bangalore, STIC Cochin, and IIT Bombay for providing ${ }^{1} \mathrm{H}$ NMR, ESR and Elemental analysis.

\section{References}

1. Sengupta A K and Gupta A A, J. Antibact. Antifungal agent JPN, 1980, 8, 7.

2. Molnar-Kimber K, Yonno L, Hearlip R and Weichman, Agents actions. 1993, 39, 677.

3. Duplantier A J and Cherg J B, Ann. Rep. Med. Chem. 1994, 29, 73.

4. Prous I R, Ed., Drugs Future, 1993, 18, 475. 
5. Seth P K and Parwar S S, Can J Pharmacol. 1965, 43, 1019.

6. Chem Abstr. 1968, 68, 2195.

7. Shetty B V, US Pat, 1970, 3, 549, 634; Chem Abstr. 1971, 75, 5940.

8. Otto H and Houlohan W W, Swiss Pat. 1971, 459, 544; Chem Abstr. 1971, 75, 20435.

9. Handfmann G E, US Pat. 1971, 3, 563, 990. Chem. Abstr. 1971, 75, 5930.

10. Pandey V K, Lohani H C, Shanker K and Dovel D C, Indian Drugs, 1983, 20, 315.

11. Pandey V K, Mishra D and Sukla S, Indian Drugs, 1994, 31, 532.

12. Pandey V K, Indian Drugs, 1988, 26, 168.

13. Pandey V K, Gupta M and Mishra D, Indian Drugs, 1996, 33, 409.

14. Pandey V K, Pathak L P and Mishra S K, Indian J. Chem., 2005, 44, 1940.

15. Vogel A I, A Text Book Quantitative Inorganic Analysis; $3^{\text {rd }}$ Ed. ELBS and Langman's Green and Co. Ltd., London. 1962.

16. Geary W J, Coord. Chem. Rev. 1972, 1, 81.

17. Angela Kriza, Cezar Spena and Mario Pleniceanu, J. Indian Chem. Soc., 2000, 77, 83.

18. Halli M B and Qureshi Z S, Indian J. Chem. 2004, 43A, 2347.

19. Cotton F A and Wilkinson G, Advanced Inorganic Chemistry; $2^{\text {nd }}$ Ed. Wiley Eastern, New York, 1967.

20. Bekhet M M and Ibrahim K M, Synth, React. Iorg. Met. Org. Chem., 1986, 16, 1135

21. Verma J K and Verma G S P, Indian J. Chem., 1982, 21A, 825.

22. Lever A B P, Inorganic Electronic Spectroscopy; Elsevier, New York, 1984.

23. Sulekh Chandra and Gupta K, Indian J. Chem. 2001, 40A, 775.

24. Underhill A E and Billing D, Nature, 1996, 210, 834.

25. Lever A B P, Inorganic Spectroscopy, Elsevier, Amsterdam, 1968.

26. Figgs B N, Introduction to Ligand Fields; Interscience, John-Wiley and Sons, New York, 1967.

27. Makode J T and Aswar A S, J. Indian Chem. Soc., 2003, 80, 44.

28. Siddappa K and Angadi S D ,Proc.Nat.Acad.Sci.India,2003, 3A, 75.

29. Chetan K M, Ashwin S P and Bharat T T, E - J Chem., 2005, 2(6), 21-29.

30. Gudasi K B, Shenoy R V, Vadavi R S, Patil M S and Patil S A, Indian J. Chem., 2005, 44A, 2247.

31. Sulekha and Lokesh Kumar Gupta, Spectrochimica Acta, 2005, 61A, 269.

32. Mishra L K, Jha Y, Sinha B K, Kant R and Sinha, J. Indian Chem. Soc., 1999, 176, 65.

33. Mahapatra B B and Saraf S K, J. Indian Chem. Soc. 2003, 80, 696.

34. Dyer J R. Application of Absorption Spectroscopy of Organic compounds; Prentice Hall of Indian Pvt. Ltd., 1986.

35. Singh N K and Singh S B, Indian J. Chem. 2001, 40A, 1047.

36. Hathaway B J and Billing D E, Coord. Chem. Rev. 1970, 6, 143.

37. Barry A L, The Antimicrobic Susceptibility test principle and practices; 1976, 180.

38. Simoncini F, Rangone R and Calanni C, Farnance Edn Prat, 1968, 23(10), 559. Chem. Abstr., 1968, 69, 109851d.

39. Seely H W and Van Demark P J, Microbes in Action, Laboratory of Microbiology, $3^{\text {rd }}$ Ed., W H Freeman and Co. U.S.A, 1981, 385. 


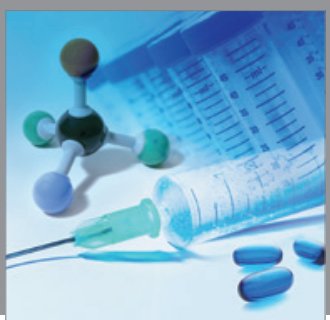

International Journal of

Medicinal Chemistry

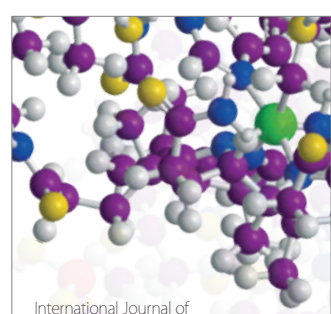

Carbohydrate Chemistry

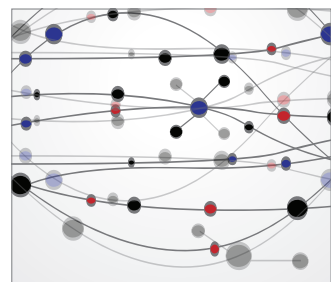

The Scientific World Journal
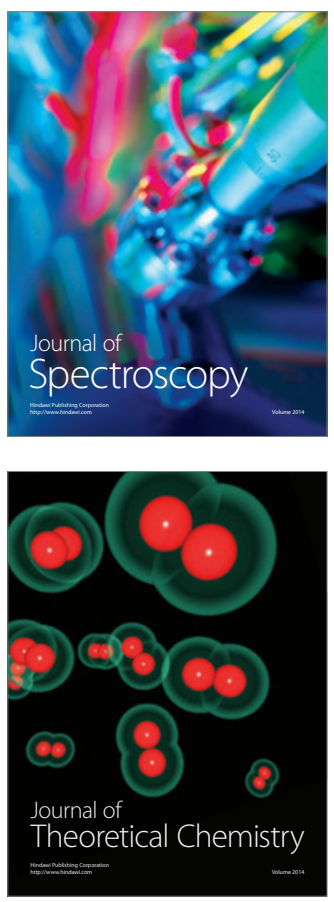
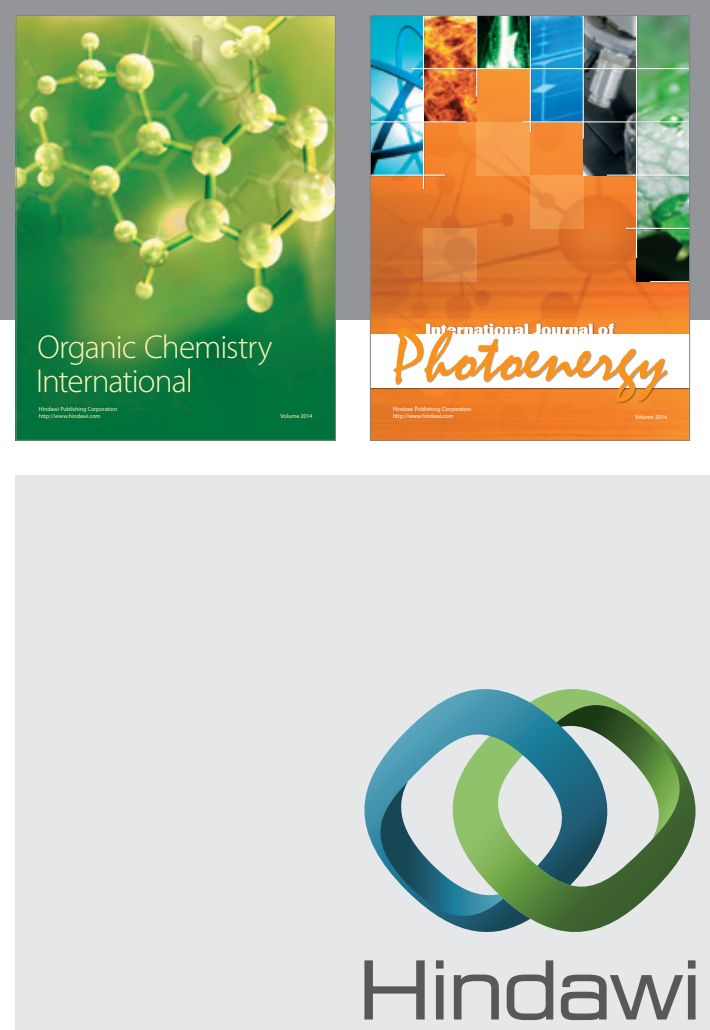

Submit your manuscripts at

http://www.hindawi.com
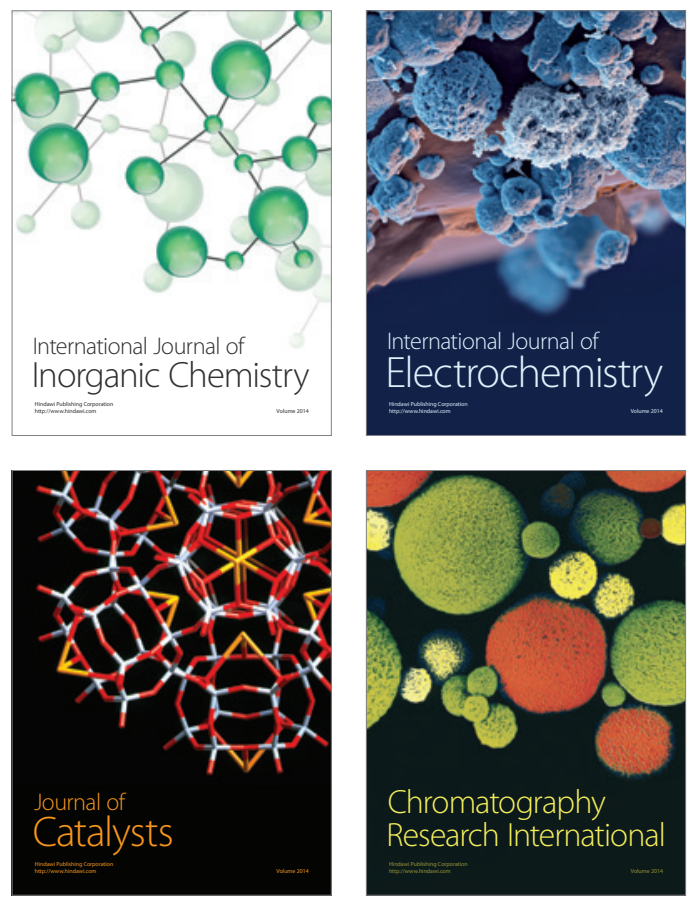
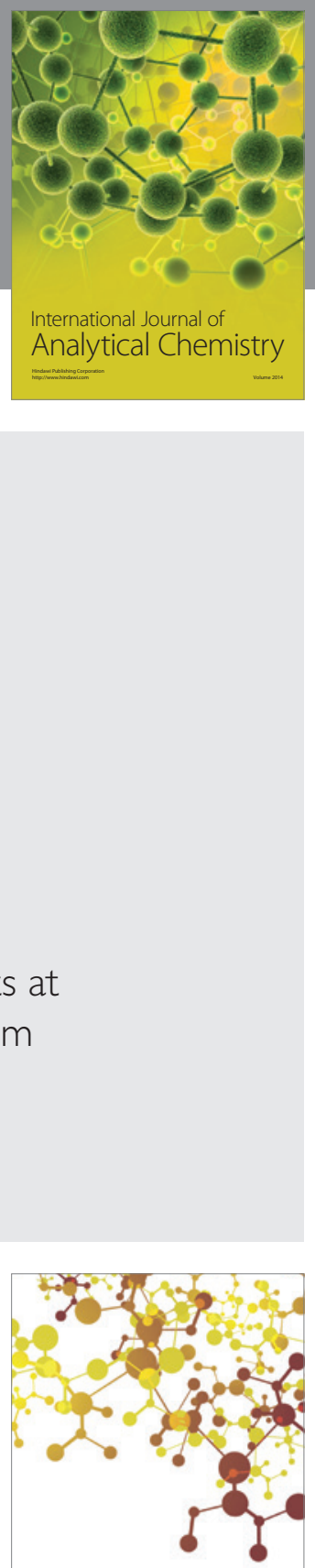

Journal of

Applied Chemistry
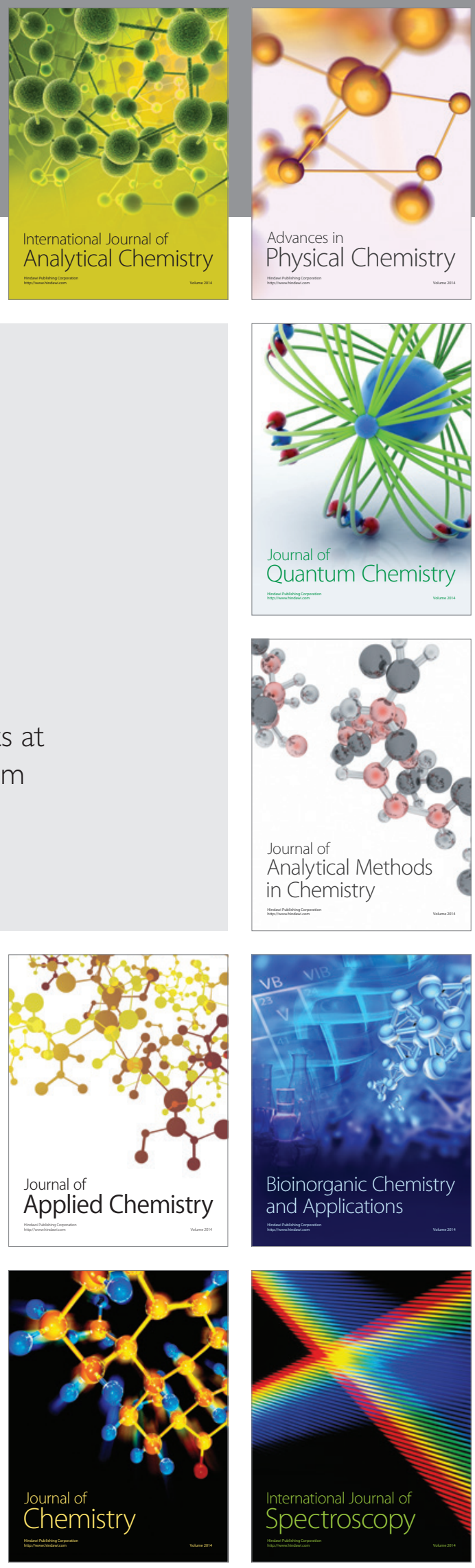